\title{
What is the place of technical and scientific service companies (TSS) in the process of developing new products? Insights on their managerial and organizational features
}

\author{
V. Lazzarotti, E. Pizzurno* \\ Università Carlo Cattaneo - LIUC, Corso Matteotti 22, 21053 Castellanza (VA), ITALY \\ ${ }^{*}$ Corresponding Author: e-mail: epizzurno@liuc.it, Tel +39-0331-572.233, Fax. +39.0331.483.447
}

\begin{abstract}
The new product development (NPD) process is composed by several phases, from concept to final production rump-up, and for each phase, it is now widely recognized that innovators can find external supporting services as design, prototyping, engineering, etc. Companies offering these technical and scientific services (TSS) are in fact more and more diffused. Literature has conducted some explorative attempts to study more in depth how these service companies are organized and managed by assuming a sort of internal perspective and analyzing the main companies' choices in terms of business model elements. In a similar vein, we deeply study the organizational and managerial features for a sample of technical service Italian companies. The empirical study has been conducted by a twofold aim: (i) to search for TSS companies that support the entire process of new product development and/or, conversely, that provide services to a smaller part of the innovation process or only on few stages in order to identify clusters of companies; (ii) once identified clusters, to study if they show differences in terms of some organisational and managerial features. The analysis of the gathered data has actually allowed to identify some typical profiles of TSS companies in which the elements of the business model take a particular and coherent combination.
\end{abstract}

Keywords: new product development, TSS, outsourcing, Italy, multiple case-studies

\section{Introduction}

Several authors offer many different reasons for the establishment and growth of firms supplying technological competences, agreeing that such TSS companies are nowadays more and more diffused (MacPherson, 1997a; MacPherson, 1997b; Howells, 1999; Chiesa and Manzini, 2000; Larsen, 2000; den Hertog e Bilderbeek, 2000; Arora et al., 2001; Muller and Zenker, 2001; Chiesa et al., 2004). Literature (Windrum and Tomlinson, 1999; Debackere 1999; Chiesa and Manzini, 2001, Chiesa et al., 2008) has also suggested several taxonomies in order to identify existing service firms. Moreover, there have been some explorative attempts to study more in depth how these service companies are organized and managed by assuming a sort of internal perspective and analyzing the main companies' choices in terms of business model elements (Hargadon and Sutton, 1997; Kelly, 2001; Chiesa et al., 2004; Chiesa et al., 2008), for example in terms of organizational structure (i.e. firm organization, human resources management, level of internal competencies, services offered); commercialisation strategy and marketing approach (i.e. clients' business sector of activity, web site approach, informal approach, etc.), management tools to provide the offered services (i.e. project organization and management tools such as intellectual property, performance measurement systems and project management techniques). However, to our best knowledge, literature contributions to the subject are still too scarce, unstructured and too concentrated on few top firms - as the American IDEO - missing the variety of hundreds of companies offering such services. In this way, they do not give relevant suggestions that can help TSS firms' managers to organize and provide effective and efficient NPD services; on the other side a deep knowledge of NPD companies can be considered as extremely significant for clients of those services. More precisely, seem to lack suggestions on how the elements of the business model should be composed in a coherent set of relationships to achieve effective and efficient NPD service. Thus it is this stream of works we attempt to help with this paper by deepening the study of the organizational and managerial features for a sample of service Italian companies. In particular, what we thought it was interesting to delve mainly into the case of companies that declare to support the entire process 
of new product development. If compared to companies offering single stage services, such companies face in fact a high complexity, given that they have to turn an abstract idea into something that is "real", "concrete", and ready to be sold. This means that they have to solve not only the problems of each phase of the NPD process, but also those relating to (i) relationships among the various phases of development, (ii) many competencies and resources needed, (iii) interaction and organizational mode with the client during the whole process (Emes et al., 2005; Jurgens, 2000; Veugelers and Cassiman, 1999). As a consequence, the picture that can be drawn analysing such companies provide interesting suggestions because it allows to appreciate the relationships among the several business model elements (and how they should be composed in order to provide a certain set of NPD services, thus giving concrete managerial suggestions in the sense clarified above). Moreover, a similar result can also benefit companies that offer just one or few stages of the process: they should obtain suggestions in order to decline in a different way their specific business model.

Coherently with the paper goal, the empirical study presented here is a multiple case study, aimed at describing how companies offering services for the NPD process organise and manage their business. Twenty-four companies have been studied through interviews conducted with all the top - or project - managers, trough a semi-structured questionnaire.

The empirical study has been conducted by a twofold aim:

- to search for TSS companies that support the entire process of new product development and/or, conversely, that provide services to a smaller part of the innovation process or only on few stages (the other extreme, i.e. only one phase) in order to identify clusters of companies. In other words, we try to identify clusters by using the element in the companies' business model representing the "completeness of the service" offered (in a continuum that goes from one stage to the whole process);

- once identified clusters, to study if they show differences in terms of the other investigated organisational and managerial features (all the other company's business model elements). In other words, we consider these other variables as illustrative ones in order to describe each emerged cluster.

The analysis of the gathered data has actually allowed to identify some typical profiles of TSS companies in which the elements of the business model take a particular and coherent combination. These clusters are described in detail in the paper, which is organised into four different sections:

- description of the conceptual context of this study, giving the basic theoretical background, concepts and definitions;

- research methodology;

- empirical study: description of the case studies and analysis of data gathered;

- managerial implications, conclusions and future research.

\section{The conceptual context of the study: the KIBS and the TSS within the new product development process}

The purpose of this section is to briefly introduce some concepts and definitions useful to understand what our field of empirical investigation is.

Several authors have studied and demonstrated that, in the innovation development field also, interaction with external entities is growing (Tidd, 1995; Veugelers and Cassiman, 1999; Quinn, 1999, 2000; Chiesa et. al., 2004; Lazzarotti and Manzini, 2009). This tendency towards outsourcing innovation has created a new category of services called KIS - knowledge intensive services (Windrum and Tomlison, 1999) - or KIBS - knowledge intensive business services (Miles, 2000; Muller and Zenker, 2001; Knoben and Oerlemans, 2006; Strambach, 2008; Horgos and Koch, 2008; Zenker and Doloreux, 2008) - characterised by a high innovative level and scientific intensity of the outputs. According to Windrum and Tomlison, 1999, 'private sector organisations that rely on professional knowledge or expertise relating to a specific technical or function domain. KIS firms may be primary sources of information and knowledge or else their services form key intermediate inputs in the products or production process of other businesses'. This kind of service can be applied to several sectors: from banking to real estate, from market research to insurance services. Among KIBS, a more specific subset can be identified, called TSS - Technical and Scientific Services (Abetti, 1989; Howells, 1999; Larsen, 2000; den Hertog and Bilderbeek, 2000; Chiesa and Manzini, 2001; Arora et al., 2001; Chiesa et al., 2008; Chiaroni et al., 2008). According to these authors, TSS are "services which rely upon technical and scientific knowledge and give an output that is, again, technical and scientific knowledge." In other words, they are service companies that sell technology and scientific knowledge. What joins these companies and differentiates them from others that fall within the definition of KIBS is therefore the nature of knowledge on which they are based and they incorporate into their services, that is technological.

Literature (Windrum and Tomlinson, 1999; Debackere 1999; Chiesa and Manzini, 2001, Chiesa et al., 2008) has also suggested several taxonomies in order to identify existing service firms: for instance, companies are grouped by type of the output provided (e.g. work-in-progress innovation that is an intermediate finding that needs to be further developed to be commercialized as an innovation; single process activity, that means TSS firms carry out, for the client company, a stage of its innovation process; whole new process development process, that means service companies start from an idea and provide their client with a new product ready to be put into production and then commercialized; technologies to develop technologies, in the case that TSS provide technologies that can be used in order to improve the efficiency and the effectiveness of the client's company's innovation process); technical and scientific competences, the TSS firm is based on and incorporates in its services, i.e. the technical or scientific domains in which an excellent knowledge level has been reached (e.g. mechanical engineering, genomic, microchip 
design); the client firm's sector of activity (e.g. mechanic, electronic, chemical, pharmaceutical); the generality of the output provided by the TSS company, a general service, i.e. aimed at supporting the innovation process of firms from different sectors or a specific service, i.e. addressed to innovative firms of a specific sector. From all these definitions and taxonomies emerge nonetheless clear that TSS services are important supports to the companies' technological innovation process.

For the purposes of this study, however, we take a narrower perspective and focus particularly on new product development services within the broader process of technological innovation. To this end a recent classification (Chiesa et al., 2008), revised and synthesized in Table 1, can help us. Firstly, it considers as relevant dimension the generality of the output provided by the TSS company, as just defined above. Regarding this dimension, we consider here the generic services without choosing any sectoral specialization. This choice is aimed to avoid results that are significantly biased by industry-specific factors.

Secondly, supported from the wide literature on the subject, it allows us to define the new product development services within the innovation process: four categories of product development activities, highlighted in bold, where companies, which we will study in this paper, are involved.

Table 1. New product development services

\begin{tabular}{|c|c|c|c|c|c|c|c|}
\hline & & & & & & \\
\hline & & \multicolumn{6}{|c|}{ Stage of the $R \& D$ process supported } \\
\hline & & $\begin{array}{l}\text { Basic } \\
\text { Research }\end{array}$ & $\begin{array}{l}\text { Applied } \\
\text { Research }\end{array}$ & $\begin{array}{l}\text { Concept } \\
\text { generation }\end{array}$ & $\begin{array}{l}\text { Product } \\
\text { design }\end{array}$ & $\begin{array}{l}\text { Engineering } \\
\text { (process design) }\end{array}$ & $\begin{array}{l}\text { Launch and } \\
\text { commercialization }\end{array}$ \\
\hline \multirow{2}{*}{$\begin{array}{l}\text { Generality of the } \\
\text { output provided }\end{array}$} & $\begin{array}{l}\text { Specific } \\
\text { service }\end{array}$ & & & & & & \\
\hline & \begin{tabular}{|l|}
$\begin{array}{l}\text { General } \\
\text { service }\end{array}$ \\
\end{tabular} & & & & & & \\
\hline
\end{tabular}

Among the many existing contributions that provide their own versions of the NPD process (here we just mention the most important, such as Urban and Hauser, 1993; Cooper, 1994; Kotler, 1997; Jones and Stevens, 1999; Haden et al., 2004; Rundquist and Chibba, 2004; Varela and Benito, 2005; Cooper, 2008; for a review see Trott, 2008), we follow here basically Verganti's definition (1997) that identifies the detailed activities composing the first three groups of relevant activities, to which we add launch and commercialization (this one, according to Kotler, 1997). In this regard, see table 2 where the detailed list of activities is shown.

Table 2. List of relevant NPD activities

\begin{tabular}{|c|l|}
\hline \multicolumn{1}{|c|}{ Phase } & \multicolumn{1}{|c|}{ Activities } \\
\hline \multirow{5}{*}{ Concept generation } & Definition of briefs \\
& Analysis of customer needs \\
& Competition analysis \\
& Definition of the generic product \\
& Generation, testing and selection of concept \\
& Assessment of the investment in new product \\
& Formulation of project plan \\
\hline \multirow{5}{*}{ Product design } & Design - architectural adaptation \\
& Choice of technologies and components \\
& Choices to make or buy design \\
& Definition of the detailed specifications of those components \\
& Design modules-components \\
& Prototyping and testing of component quality \\
& Integration of modules-components \\
& Test Product Quality \\
& Optimization \\
\hline \multirow{5}{*}{ Engineering (process design) } & Configuration of the production process \\
& Design of machines and tools (dies, tools etc.) \\
& Development of part programs to control production machines \\
& Definition of schedules and work instructions \\
& Definition timing and methods and workforce training \\
& Pre-implementation \\
& Start production \\
\hline Launch and commercialization & Launch the product \\
& Produce and place advertisements and other promotions \\
& Fill the distribution pipeline with the product \\
& Pricing \\
\hline
\end{tabular}


Another very interesting aspect debated in literature is regarding the choice of the governance mode "right" to cooperate (i.e. cooperation between TSS companies and their customers) as it is demonstrated by very recent contributions (van de Vrande et al., 2006; Ojasalo, 2008). The term "governance mode" refers jointly both to the particular organizational structure (i.e. alliance, outsourcing, etc.) and its ingrained managerial features (i.e. level of integration; reversibility, level of control over activities, etc). Thus, network organizational form and network management essentially belong together. For this area of studies, literature has already given relevant theoretical frameworks to rationalize the involved variables. For example, the broad set of different organizational structures to collaborate has been studied and categorized as well as the factors driving the choice of such governance modes (Chiesa, 2001). However, the application of these frameworks on concrete cases in order to verify their validity is still scarce as it is declared by the same authors cited above. Thus, the analysis of the TSS companies in this study can provide interesting insights also in such direction. Specifically, according to literature suggestions, the decision-making factors that influence the choice of the governance mode can be grouped in three categories, respectively relating to: i) the objectives of the collaboration, ii) the content of the work to carry out in collaboration, iii) the nature of the partners involved.

As concerns the first factor, a broad set of objectives often requires a long-term relationship and relevant resources from each partner, thus leading to governance modes more integrated than pure outsourcing, configuring a sort of alliance. In contrast, when a precise and limited objective is defined, outsourcing is appropriate (Chiesa, 2001; Hermens, 2001). Governance modes more reversible, less controlled and characterized by a low level of contractual formalization have to be chosen also when the objective of the collaboration is "maximise learning from partners" and thus sharing knowledge (Lawson et al., 2009). Informal mechanisms seem in fact to facilitate information flows and know-how diffusion among the partners. As concerns the second factor, i.e. the content of the work in collaboration, the relevance of this for the customer firm's competitive advantage seems to be an important driver affecting decisions about the governance mode of collaboration. When collaborations concern a firm's core technological competence, it is critical to keep control over such knowledge (Chiesa, 2001). Moreover, due to the fact that competence building requires time, the horizon of these collaborations is usually long. Hence, when there is a high potential for a firm to create and/or maintain competitive advantage through cooperation, governance modes characterized by high integration and high control level are the most appropriate. On the other hand, collaborations on non-core technologies and competences do not require strong control. Thus, companies tend to maximize flexibility and to minimize time/cost for establishing the relationship. The customer's familiarity with the content of collaboration is another example of this second factor. If a firm lacks technical or market competencies, literature suggests that more integrated and formalized modes of collaboration (i.e. alliances or also outsourcing but "reinforced" by structured contracts that explicitly include a strong planning and control in order to increase the level of control over activities and results) are preferred since these allow to access to the partners' complementary resources (scientific, technical, knowledge, managerial capabilities), whilst pure outsourcing normally does not allow it. Lastly, concerning the third factor (i.e. the nature of the partners involved), cultural differences/distances between partners seem to be important (Folta, 1998) as well as the suggestions by transaction costs theory (Williamson, 1985). "Distance" among partners, which come from different countries or sectors, causes information asymmetry leading to very reversible and low-commitment level governance modes, such as outsourcing. The relative bargaining power among partners seems to be another factor. A more powerful partner (usually larger in terms of size) tends to choose more integrated and/or formal modes of collaboration in order to impose the desired direction to the collaboration (Chiesa, 2001). Obviously, the various factors may lead to different requirements causing some trade-offs. For example, collaborations concerned with all the NPD stages (i.e. broad objectives) require low reversibility but if, at the same time, they are carried out with customers characterized by relevant cultural distance, this factor can push in a different direction. Thus, in most cases, for decision making it is necessary to balance opposite forces (Hendry, 1995).

In summary, in this work we focus on services TSS intended as new product development services that support one or more stages of development of an innovative product without having a specialization addressed to a specific industry. We will devote particular attention to managerial and organizational aspects that characterize the TSS as well as the way such companies organize the relationship of collaboration with their customers (i.e. the organizational mode of collaboration).

At this point we have all the elements to study the selected companies that provide these services, after a brief clarification about the adopted methodology.

\section{Research methodology}

The research method adopted in this work is based on a multiple case study. Despite the widely acknowledge limitations of this approach, especially in terms of reliability and validity (Ginsberg and Abrahamson, 1991; Yin, 2003), the case study method has the ability to capture the full complexity of the studied phenomenon, including its 'softer' aspects. Given that the aim of our empirical study was to investigate TSS practices in-depth, the aforementioned advantage of the case study method was a critical factor in selecting the research approach. Information was collected through direct interviews with companies' management and internal documents were also consulted.

In order to appreciate the main analogies and differences among companies, a structured cross-case analysis was carried out, through which data and information collected have been elaborated, categorised and compared in order to point out analogies and differences, so as to draw a reliable and synthetic picture of the sample analysed. More precisely, data and information gathered through the case studies were manipulated before being analysed. In particular, we applied the following techniques (Miles and 
Huberman, 1984): (i) data categorisation, which requires the decomposition and aggregation of data in order to highlight some characteristics (e.g., project organization and management in terms of several variables as reported in section 4) and to facilitate comparisons; (ii) a preliminary within-case analysis was performed with the purpose of considering each case study as a separate one and systematically documenting the variables of interest defined in the questionnaire; iii) explanation-building procedures were carried out so that the relationships between some variables were identified (e.g. factors affecting decisions about the organizational mode with customers); (iv) a cross-case analysis was undertaken for comparing the studied variables that emerged in each case study in order to define clusters of companies.

Moreover, the main evidence and findings emerging have been discussed with some of the people interviewed, in order to verify their validity. Only one firm has been excluded by the analysis because clearly emerged - during the empirical research - as unable to offer a various set of NPD services.

The applied research methodology had two main limitations. First, because the empirical base was mainly built up from personal direct interviews with the company's top manager, the results are susceptible to bias arising from distorted and subjective interpretations and rationalizations. Second, as in most case studies, the empirical research does not permit any systematic generalisation. That said, the aim of this empirical investigation was not to generalise, but rather to offer a detailed description of the phenomenon and to offer some new insights for future investigations, aimed at generalising results (Eisenhardt, 1989).

\section{The empirical study}

4.1. The sample: the empirical study presented here is a multiple case study, aimed at describing how companies offering services for the whole NPD process organise and manage their business.

Limiting the search to a first step, we decide to start by focusing on a population - and consequently selecting a sample consistent with these criteria:

- firms that have declared able to support the entire product development process;

- firms that are not specialised in supporting NPD within a specific industry;

- private-owned firms that have NPD services as core business;

- firms able to develop a physical finished good and, among the sectors, excluding those that show specific scientific peculiarities in NPD processes (Trott, 2008) i.e. software, pharmaceutical, chemical or biotechnological companies.

Twenty-five companies with these features have been studied, as reported in Table 3 through:

- interviews: more than 3 telephone and in-person interviews were conducted with all the top - or project - managers, trough a semi-structured questionnaire. The questionnaire is too wide to be included in this paper; however, respondents were asked questions related to:

o The NPD company organization as: (i) firm organisation and services offered, (ii) HR management, (iii) knowledge management, (iv) firm structure, (v) competencies and collaborations;

o The commercialisation and internationalisation strategy intended as: (i) sale of NPD services, external communication, (ii) CRM (iii) clients' business sector of activity, (iv) client searching, (v) competitors, (vi) location of clients and (vii) pricing;

o The project organization and management, in terms of (i) technical interaction with clients, (ii) organizational mode of collaboration with customers, (iii) commercialization phase, (iv) intellectual property management, (v) performance measurement system, (vi) projects average duration, (vii) projects per years, (viii) project management and (ix) project work organization.

- documents, both internal (provided by interviewed people, such as internal project reports and prototypes) and public (available, for example, on the web-sites of companies, such as presentations and promotions).

The main conclusions of the study are presented in the following section.

4.2. Research findings: in this paragraph, the organizational and managerial features of the studied Italian NPD firms are described. First of all, the main analogies are analysed, i.e. those elements that characterise in a very similar way all the companies studied; then, the significant differences are pointed into evidence, i.e. those elements in the business model that significantly diverge among companies, with the aim to verify whether some clusters of companies can be identified.

4.2.1. Analogies among the Italian NPD firms: firstly, analogies are described in terms of: company's organisation, commercialisation and internationalisation strategy, project organisation and management.

\section{Company organisation}

Firm structure: while the firms are showing a different organisation in relation to their dimension (in term of employees), all of them - even the smallest - follow a common approach: the matrix management and, more often, a strong (project) matrix. A project manager - who is primarily responsible for the project - is always identified. Functional managers provide technical expertise and assign resources on an as-needed basis. 
Table 3. The NPD firms interviewed

\begin{tabular}{|c|l|l|l|}
\hline & Company & Revenue & Employees \\
\hline 1 & Appliances Engineering & $1-5 \mathrm{mln} €$ & $11-20$ \\
\hline 2 & Attivo Creative Resource & $200.000-1 \mathrm{mln} €$ & $1-10$ \\
\hline 3 & Creanova & $200.000-1 \mathrm{mln} €$ & $1-10$ \\
\hline 4 & Design Continuum & Confidential & $11-20$ \\
\hline 5 & Design Group Italia & $1-5 \mathrm{mln} €$ & $11-20$ \\
\hline 6 & Disegno Bello & $200.000-1 \mathrm{mln} €$ & $1-10$ \\
\hline 7 & DNA & Confidential & $1-10$ \\
\hline 8 & Esseti & Confidential & $1-10$ \\
\hline 9 & Far Design & $<200.000 €$ & $1-10$ \\
\hline 10 & Fox Bit & $1-5 \mathrm{mln} €$ & $51-100$ \\
\hline 11 & James Irvine & $200.000-1 \mathrm{mln} €$ & $1-10$ \\
\hline 12 & MR\&D Institute & $>5 \mathrm{mln} €$ & $51-100$ \\
\hline 13 & Partec & $<200.000 €$ & $1-10$ \\
\hline 14 & Pininfarina Extra & $>5 \mathrm{mln} €$ & $21-50$ \\
\hline 15 & Pro Design Italia & Confidential & $1-10$ \\
\hline 16 & Promau & $1-5 \mathrm{mln} €$ & $51-100$ \\
\hline 17 & SB3 & $1-5 \mathrm{mln} €$ & $1-10$ \\
\hline 18 & Sintesi AB & $200.000-1 \mathrm{mln} €$ & $1-10$ \\
\hline 19 & Sowden Design & $200.000-1 \mathrm{mln} €$ & $1-10$ \\
\hline 20 & Spring Design & Confidential & $1-10$ \\
\hline 21 & Studio Bonfanti & $200.000-1 \mathrm{mln} €$ & $1-10$ \\
\hline 22 & Studio Primalinea & $200.000-1 \mathrm{mln} €$ & $1-10$ \\
\hline 23 & SZ Design (Zagato) & $>5 \mathrm{mln} €$ & $51-100$ \\
\hline 24 & Vegni Design & Confidential & $1-10$ \\
\hline 25 & VIP Technologies & $<200.000 €$ & $1-10$ \\
\hline & & & \\
\hline
\end{tabular}

Human resources management: this can considered a key point for the success of the NPD firms, which base largely their activities on the competencies and experiences of their employees. In particular, the critical factors in HRM for NPD companies are: (i) the recruitment of talents or well-trained personnel; (ii) the continuous improvement of the capabilities; (iii) job environment and team working. Significant time and resources are dedicated to improving performance in these three topics. In terms of profile, usually graduates in Economics, Engineering (mechanical, electronic, management...) and Industrial Design can be found, but also Design licentiates. A significant percentage of employees are very young.

Knowledge management: even if the formal storage of past projects results and solutions is recognised to be effective and efficient, the Italian NPD firms usually do not use sophisticated tools to this aim. Even when designed and realized, these archives are not easily accessible and commonly used. Informal and personal relationships and networks generally represent the most important KM system, together with the storage of prototypes and pictures of past developed products.

\section{Commercialisation and internationalisation strategy}

Sale of NPD services and external communication: the market of services for NPD is still unknown, even if the externalisation of NPD seems to be increasingly relevant. Main consequence of this lack of knowledge, shared language and sufficiently precise and widespread classifications is that the marketing of the services offered is a very difficult task for NPD service companies, which have to rely on their own capability of self-introduction to the market. More precisely, it has been recognised that it is very difficult for NPD companies to clearly communicate what they are really able to do. Web-sites and visiting professional fairs represent the main channels for the external communication. As a consequence, information given on the web sites, if used, tries to be rich, detailed and well structured. A section, called "credentials" is frequently used to better clarify the company's activity and qualification, in which previous projects of new products are described. This difficulty in communication is also recognised as the main barrier in the acquisition of new clients, together with the problem of evaluating the "value" of the services offered.

Customer relationship management: the Italian NPD companies show, on average, $80 \%$ of continuative relations against a $20 \%$ of single projects committed. All main CRM techniques are well known and widely used. 
Prices and margins: the complexity of the project determines the price (from few thousands Euros to hundred thousands Euro); the average is around $80.000 €-100.000 €$. In price definition the following parameters are taken in consideration:

- time (in term of hours - or days/weeks - required to perform the project);

- kind of activities performed. In fact not all activities have same evaluation (mechanical design is considered less than electronic design, for instance);

- $\quad$ kind of resources employed (human, technical, etc.);

- estimated value of the product on the market .

The average expected margin on the projects is around $20 \%$.

Project organisation and management

Technical interaction with clients: the level of computer-aided support reached in the last years, above all concerning innovative solutions for remote collaboration, is extremely advanced. Even if software and ICT tools for remote collaboration are well known by companies, they are far from being diffused and widespread adopted. All NPD firms agree that the main cause reside in the client culture, which suggests adopting a more traditional approach. Companies still prefer personal relationships in NPD. As a matter of fact, even companies with a size and a level of project complexity totally adequate to the use of remote ICT tools, base their co-operation with clients upon:

- periodical meetings/contacts with the customer in order to define the concept (through the due brainstormings), to consult together with the technicians and to present the work in progress and the finished project;

- traditional communication tools, such as fax and e-mail.

Also within the NPD firm itself, such radical changes are not undertaken, and traditional updates and periodical meetings among members of the inter-functional team take place.

Commercialisation phase: this phase of the NDP process is strictly controlled by the customers and it is never outsourced to NPD firms, even when such firms offer adequate competences and skills. It is quite evident that this is probably the most critical phase for clients to ensure the appropriability of their innovation.

Intellectual property management: in all the observed companies, by contract, the intellectual property of the new product is owned by the clients. The patenting process is usually outsourced to specialists and considered as a standard service for the clients.

Performance measurement system: typically, the performance measurement system (PMS) in NPD projects takes into consideration conventional economic performance indicators (costs, timing, quality, resources, clients satisfaction, level of sales of the new product compared to forecasting, etc.). In several NPD firms, it has been observed an increasing diffusion of approaches to the measurement of innovative performances (i.e. commitment and creativity of employees, new clients and other qualitative indicators as company reputation) aimed at monitoring the company's innovative capability, processes and results (Chiesa et al., 2006).

Project management: a project manager - who is primarily responsible for the project - is always identified. Functional managers provide technical expertise and assign resources on an as-needed basis. Project teams are created on the basis of adequate skills and knowledge of the specific customer. Basic approaches of project management (Traditional Project Management as well as Closing Critical Chain Project Management) are well known and widely used and the project manager and the team use the most diffused tools, software and methodologies in the technical-design area (concurrent engineering, Design for $\mathrm{X}$, etc) as well as in the managerial one (forward engineering, WBS, milestones, Critical Path Method - CPM, Gantt diagrams, etc). The project teams usually interact with the project's client in correspondence of the defined milestones, when the state of the art is verified, the possible delays are defined and the needed corrective actions are identified, and all information about the project is shared. These meetings are also critical for evaluating qualitative "soft" factors, such as the development of experiences, in a business collaborative atmosphere.

4.2.2. Differences among the Italian NPD firms: secondly, differences are here analysed in terms of company's organisation, internationalisation, commercialisation strategy and project organisation and management.

\section{Company organisation}

Firm organisation, services offered and related competences: size is significantly different among the studied firms. Companies can be constituted by a limited staff - from 1 to 10 employees - or be structured with highly remarkable resources (from 51 to 100 employees). In the first case the firm structure results extremely flat, with owners and employees to fulfil basically the same tasks. In small companies, few employees manage the entire project, occasionally creating inter-functional teams with client's people. Big companies are more structured and present a formalised structure, with the following functions (that correspond to services offered to the customer and related competences, along the NPD process):

- Marketing: this function is dedicated to strategic marketing and it is able to carry out any qualitative and quantitative analysis (trend definition, product placement, market share calculation, etc.);

- Industrial Design (ID): this function generally works in coordination with the Mechanical and the Electronics Design departments in order to merge and coherently integrate the various ID objectives (such as strategic design, product and graphic design and brand development, ergonomics, functionality of shapes, materials, ...). This function/unit usually involves much specialised personnel, it uses state of the art knowledge and technology and, hence, it provides a high 
quality outcome, integrated with the technical solutions adopted. It should be noted that some firms tend to specialize themselves on the more technical aspects of the industrial design. In these "technical oriented" firms, ID service is thus only partially offered, since aspects as brand development or aesthetic design are neglected.

- Mechanical Design: Mechanical Design is usually performed at excellent levels. New technologies are constantly adopted, with the aim to deliver new solutions that better deal with human factors (i.e. specific needs and constrains that derive from the direct interaction among human beings, products and technology) and with the growing sensitiveness to aesthetics.

- Electronics and Software Development: very few companies are actually able to offer this part of the NPD services according to the state of the art knowledge and technology. Indeed, some firms completely lack such competencies. As a consequence, when a new product requires electronic or SW subparts, these firms acquire outside a "shelf solution" or, in some case, collaborate with external sources (in some case with the clients themselves). Also "technical oriented" firms (which focus mostly on the technical aspects of the NPD, as defined above) has proved very partial experiences in this field.

- Engineering: the supply of these services implies for significant investments. Due to the high rate by which the necessary assets become obsolete and the high investments related, only the most developed firms can afford pre-production and rapid-prototyping machinery. Moreover, this set of skills usually includes laboratory test and analysis, production of simple prototypes and supplier selection, competencies normally diffused in all the studied companies.

Competencies and collaborations: the mix of internal/external competencies is extremely various. In big firms the access to external sources of knowledge and technology is very low (just rapid prototyping or software development); these companies relies only on internal workforce. If the case, the external partnerships are arranged with a twofold aim. Sometimes, the external collaborations are stable and they cover the range of services offered by the NPD firm that, in this way, can enlarge and enrich the specialised internal competencies. In other cases - especially where a wide range of services is performed by a considerable internal staff - the occasional external collaborations are useful to support NPD company in periods of intense work.

These collaborators are often professionals or small firms specialised in one phase of NPD process. Thus, if NPD firms can have a maximum of three external established collaborations, other NPD firms can have tens of external partnerships. Rarely, the collaboration involves universities. Usually, partners are involved with different types of collaborations (and consequently with different levels of coordination and integration, according Chiesa and Manzini, 1998), for instance: (i) as members of the team developing the new product, or (ii) as simple suppliers.

\section{Commercialisation and internationalisation strategy}

Clients' business sectors: almost all companies support NPD process in several different industries and it has not been noted a clear association between specific products and specific group of NPD firms (the client's business sector crosses among firms' groups). Automotive, telecommunication and electronics are the most diffused (more than $70 \%$ of NPD firms have clients belonging to these industries). Anyway, some companies seems to be focalized on some sectors while for other TSS the choice is broader.

Location of the client: NPD firms are positioned close to the national economic neuralgic centres. For these companies, the location in an economically important area is relevant also to be close to potential customers. Furthermore, it allows a NPD company to be better and faster informed about their working field: conferences, seminaries and other similar activities are held usually in such economic centres. Some NPD companies serve clients in Europe and worldwide, above all the biggest ones. Anyway, interviews proved that clients' location rarely causes managing problems for Italian NPD firms, due to the availability of electronic tools. However, the physical distance can cause problems: the nature of the activities (i.e. creative ones) leads to the need of a direct contact with its own customers.

The internationalisation strategy: the internationalisation strategy of companies seems to be a critical point, since globalisation allows to significantly widening the potential market. Having a geographically wide market immediately points out the "distance" problem. Together with the "physical" problem described above, also cultural, legislative and linguistic differences are factors that tend to undertake growing importance, and above all when the concern different continents. Furthermore, an international market seems to be accessible only by big service firms. As a matter of fact, large dimensions seem to attract better skills, which, in turn, influence the diffusion of the firm's work. Generally, it has been observed that companies with similar skills but different dimensions (small vs. big) cover different sizes of markets, where the main distinction is between intra (i.e. small companies as Fardesign, Bonfanti) and inter-continental ones (big companies such as Design Group Italia, Attivo Creative Resource).

When the intercontinental market is becoming consistent, local needs start to emerge and thus companies have to be open new offices abroad (as in the case of company "MR\&D Institute"). Physical proximity, obtained through new seats, will answer the aforementioned needs of filling cultural, linguistic and legislative gaps. De facto, new seats are never as big and structured as the headquarters and do not have all the skills of the latter either. They focus mainly on marketing, market analysis and design activities - that is on those factors that are more distance-sensitive - while the more technical phases of each project will be forwarded to the head office (Design Group is an example in this sense).

From this point of view, another factor seems to affect the internationalisation strategy: the firms' main focus of activity, i.e. the phase, within the NPD process, to which the company dedicates its main resources and/or those in which it is considered as excellent: 
- An orientation to the "soft" design aspects (i.e. style, elegance, interface innovation) of NPD seems to experience a wider geographical feedback than technical ones (for example, this is the case of Pininfarina Extra, Zagato, which have an image and brand appreciated worldwide).

- In contrast, an orientation to technical contents tends to become anonymous, as often lacking of a proper image. Without the necessity of looking for a certain line or style, the attractiveness for customers to face more expensive and difficult collaborations with distant partners seems to disappear (as declared by Pro Design, VIP Technologies). This, of course, limits the possibility for NPD companies of offering their services to geographically far companies. Moreover, the very technical part of the project is often developed in collaboration with the client itself, due to the fact that technical knowhow of its products is hardly surpassed by that of the NPD firm. Thus, normally, customers are looking for a geographically closer partner rather than one which is further away.

In conclusion, more design-oriented firms will thus tend to have a more geographically heterogeneous market, while technical oriented ones will basically work with national or even regional clients.

Clients searching: Shortly, the main potential channels for customer retrieval are: brand importance (of the NPD firm), personal acquaintances, word of mouth, marketing/trade dedicated employee, Web site and presence at professional fairs. Theoretically, each kind of NPD firm could define its specific mix of the aforesaid channels, thus distinguishing from the others. Practically, the importance of the personal acquaintances and word of mouth channels is a common point between all kinds of NPD firms, although Web mode seems more diffused for companies providing the entire set of NPD services.

Competitors: firms able to offer a very complete set of NPD services face a strength international competition (IDEO, Well Design, Cambridge Consultants, are the most famous competitors). On the other hand, firms which are specialised in few phases compete mainly on a local basis, with very small firms and professionals.

\section{Project organisation and management}

Project average duration: in general what influences the duration of a project are the technical (mechanical and electrical, ...) components and phases more than design ones, while the overall length is related to the complexity of the project and, mostly, to the number of phases covered. Normally, firms that cover the entire NPD process have average one-year duration, period that is reduced to 2 months in firms covering only few phases.

Project work organization: inter-functional teams, to which also customers participate, are diffused in almost all TSS companies. Anyway, it is verified by the information gathered, how:

- Smaller companies (maximum 4-5 employees) carry forward projects involving a single internal person - or a couple at most - and organising at times inter-functional teams together with part of its client's staff (Fardesign, Bonfanti, Gloss Design). Also firms constituted by a range of 6-10 people, work in a similar way, having 2-people-team supervised usually by one of the company managers or seniors (Attivo Creative Resource, Studio Prima Linea). This is a consequence of small firm dimensions and of homogeneous internal skills. In fact, at these levels, the company structure is very flat and similar skills are present, which obstacles the creation of structured teams. Project complexity is usually coherent with these firms' capabilities, and excessively long and complicated developments are carried forward together with the customer's personnel.

- Differently, it is with a more consistent, structured and heterogeneous staff that specific-competence-mixed internal workgroups start to be observed. Anyway, joint-work together with the client does not disappear in these cases (MR\&D Institute, Design Continuum).

Organizational mode of collaboration: TSS companies providing services in all the NPD stages are linked to their customers by long-term relationships. This leads to more integrated mode of collaboration (e.g. a long- term structured contract is defined to reinforce outsourcing) with respect to the situation of companies engaged in a precise and limited scope (i.e. a specific phase of the NPD process). A similar impact is provided by the fact that the content of the collaboration is strategic or not for TSS customers. Also a low familiarity with the content of work by customers drives the governance mode towards highly controlled forms. On the other hand, the objective of maximisation of learning between partners, quite common in several relationships, seems to lead to less formalized modes in order to encourage information flows and knowledge sharing. As it is perhaps obvious to expect, we note also that cultural distance between partners is claimed by those TSS companies whose customers are international. This factors seems to encourage very reversible and low-commitment organizational mode. Finally, if the customer is larger than TSS company, it seems to prefer more structured modes in order to drive collaboration in the desired direction.

4.2.3. The emerging clusters of NPD companies: all of the interviewed companies have described themselves more or less explicitly, through words and images, as capable of performing any necessary activity to create a functioning product out of an idea. In order to completely develop a new product an NPD firm should at least be skilled in the market analysis, industrial design, mechanical, electric and electronic design and software development areas. But only few companies trace the described profile, while the rest cover just a part of the complete development process. The most widespread missing skills of such companies are the electronic/software development ones. This means they will be able to conceive and design a certain variety of products, but won't be able to complete (nor autonomously nor through their nets of collaborators) the development of an object that would require electronic or software applications. Lacking of one or more skills to be considered a complete NPD firm, we suggest to name them "Integrated Industrial Design companies" (ID+ in figure 1) according to their own high-level design competences. 
Additionally, a second factor that must be taken into consideration is the omission or distortion of published information by NPD companies. The NPD companies, during interviews, admit they are involved with just a part of the NP development process clarifying that there is an informative gap between declared and real services. This affects the firm-customer relationship, distorting the information the latter perceives.

Figure 1 summarised the effect of lack of definitions and clustered firms into categories according to their level service and gap between declared and offered services. It highlights also that bigger companies need a lower level of outsourcing.

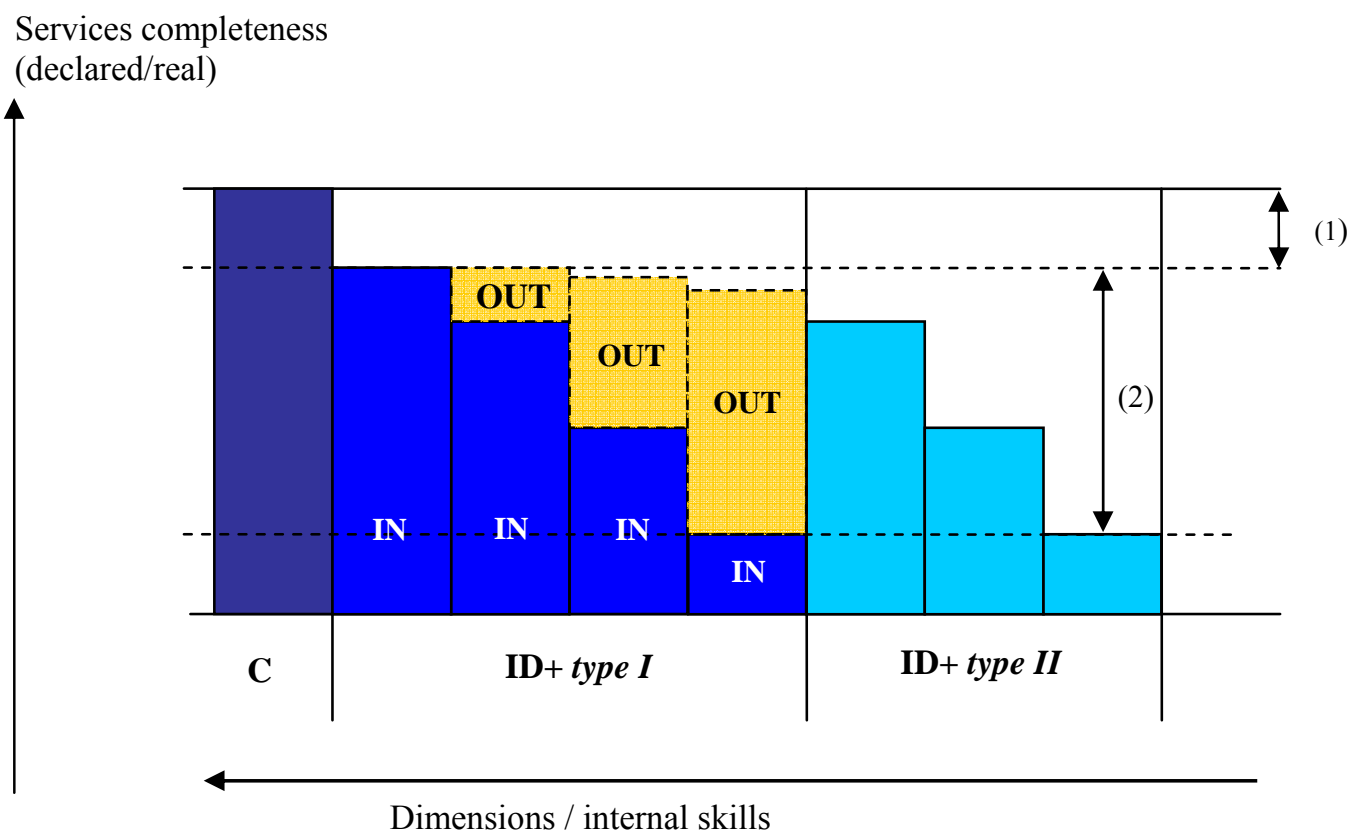

(1) gap caused by distortion of information and lack of common definitions

(2) gap caused by information asymmetry firms - clients

Figure 1. The lack of common definitions and firms' categories

In detail, the results of the empirical analysis showed that the considered market is rather fragmented in terms of services offered. However, thanks to the analysis of analogies and differences described above, some clusters can be identified. They can be represented as in Figure 2, considering at first the relationship between the completeness of the service provided (i.e. all the phases of NPD are supported) and the level of one of the managerial variable studied above (i.e. the level of internal competences). They are named as follows:

- Complete new product development firms (identified in the Figure 2 with the letter " $\mathrm{C}$ "): companies able to plan and develop a complex product, providing a high level of novelty and supporting the client in all the phases of the NPD process and to offer strategic consulting as well;

- Integrated industrial design firms (ID+) type I: companies which possess competencies in all NPD fields, except for software and electronic or electro-technical functions. In some cases all these competencies are internal, in other cases they rely on an effective external network of partners;

- Integrated industrial design firms (ID+) type II: however they present themselves as able to offer services as in the previous group, these small companies tend to be specialised in one (or more) phase of the NPD because they rely only on internal competencies; in consequence, services offered are decreasing whether internal resources decrease.

Thus, we found that the main difference in terms of competences is concerning the electronic and software skills. The figure can also be interpreted in a dynamical sense and it may represent a sort of path that companies can follow to increase the completeness of the service. In fact it highlights how companies with more expertise are able to offer a more complete service (cluster C); thanks to the use of external expertise, along with those inside, companies are able to maintain the completeness of the service (type I); instead, with the decreasing of internal expertise, if companies do not resort to external competences, completeness of service decreases significantly (type II). In the studied sample all companies started their history as "type II". Some of them, after a number of years, having observed growing requests by clients in different areas of knowledge, began to fill missing competences through the network of collaborations, transforming themselves into ID+ type I. If these requests started to be established these companies internalized all collaborators, adding electronic and software know-how, transforming into C NPD firms. 


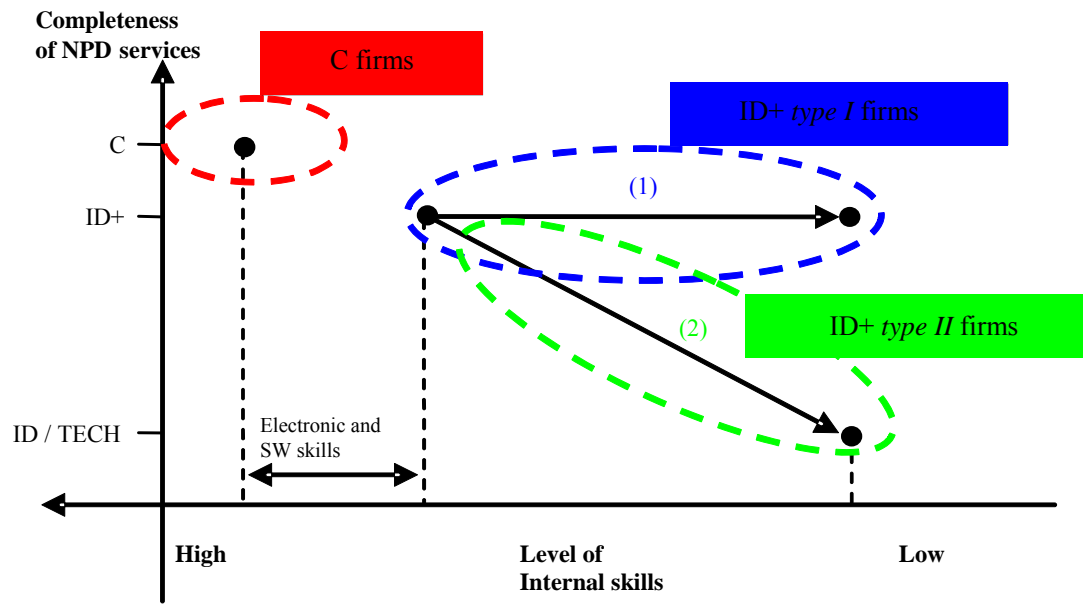

Figure 2. NPD emerging clusters

Secondly, Table 4 summarizes information about the clusters of companies as concerns the other organizational and managerial factors, allowing a deeper understanding of their business model. Also on these factors, it is possible to appreciate a growing complexity and richness passing organizational factors by firms named $\mathrm{C}$ to the ID+, type I and II.

Companies belonging to cluster $\mathrm{C}$ are normally big firms with an articulated and complex organizational structure, whilst the other are usually smaller and, above all, showing an informal organization. Consequently, such "complete" firms can boast competences that are organized in functional units able to work together by sharing expertise along the whole NPD process. Thus, the range of services offered is very broad and the level of internal expertise is wide and deep, with advanced skills also in the electronic and software fields. The scope of these enterprises is generally international (in terms of both customers and competitors' nature) and that is what differentiates them from others in particular, although the clients' business sectors are usually very similar. In short, the complexity is really more and this is also evidenced by the longer duration of the undertaken projects. Moreover, although the mode of finding customers seem to be rather informal or quite traditional for all types of firms (i.e. personal acquaintances, word of mouth, marketing/trade dedicated employees) more sophisticated means of communication seems to be spreading (i.e. through Web site) in the "complete" companies. Finally, it is nevertheless interesting to note that the reputation of all the studied companies is strictly limited to professionals and there are very few cases where the brand is known and therefore perhaps rewarding (i.e. Pininfarina Extra and Zagato). However, this confirms the importance of enriching the empirical evidence on this type of service companies. As concerns the organizational mode of collaborations with customers, some factors (i.e. the broad set of objectives of collaboration covering all the NPD stages, as well as the content of collaboration, usually strategic for the customers of TSS companies in cluster C) seem to lead to integrated and formalized modes of collaboration. Thus, very often, a structured contract is defined where the main terms of the agreement require that TSS company is assigned a precise output, whose characteristics and functionality are clearly described in quantitative, measurable terms (i.e. timescales, costs and outputs of each TSS task). On the other hand, cultural distance with customers, also quite common, seems to lead in the opposite direction.

Other factors driving the choice of governance mode of collaboration (i.e. the emphasis on learning maximization from partners as well as the customer 's familiarity with the content of cooperation) show a different impact among the companies but they are not associable to a specific cluster. Thus we report them in table 4 among the analogies.

Table 4. Organizational and managerial features and firms clusters

\begin{tabular}{|c|c|c|c|c|}
\hline & Category & C & ID+ type I & ID+ type II \\
\hline \multirow{4}{*}{ 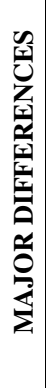 } & Services offered & $\begin{array}{l}\text { All NPD service are available } \\
\text { (marketing, industrial design, } \\
\text { mechanical design, electronics - } \\
\text { software, engineering) }\end{array}$ & $\begin{array}{l}\text { Complete NPD service, excluding } \\
\text { electronics and software (marketing, } \\
\text { industrial design, mechanical design, } \\
\text { partially engineering) }\end{array}$ & $\begin{array}{l}\text { Specialised in one or few services } \\
\text { (among: partially marketing, } \\
\text { industrial design, mechanical } \\
\text { design, partially engineering) }\end{array}$ \\
\hline & Size & Large & Medium and small & Medium and small \\
\hline & Competences & Only internal & $\begin{array}{l}\text { Internal competencies are, in most of } \\
\text { cases, complemented by a network of } \\
\text { external expertise }\end{array}$ & Only internal \\
\hline & Competitors & International NPD firms & None or other local NPD firms & Local specialised firms \\
\hline
\end{tabular}


Table 4. (cont'd.) Organizational and managerial features and firms clusters

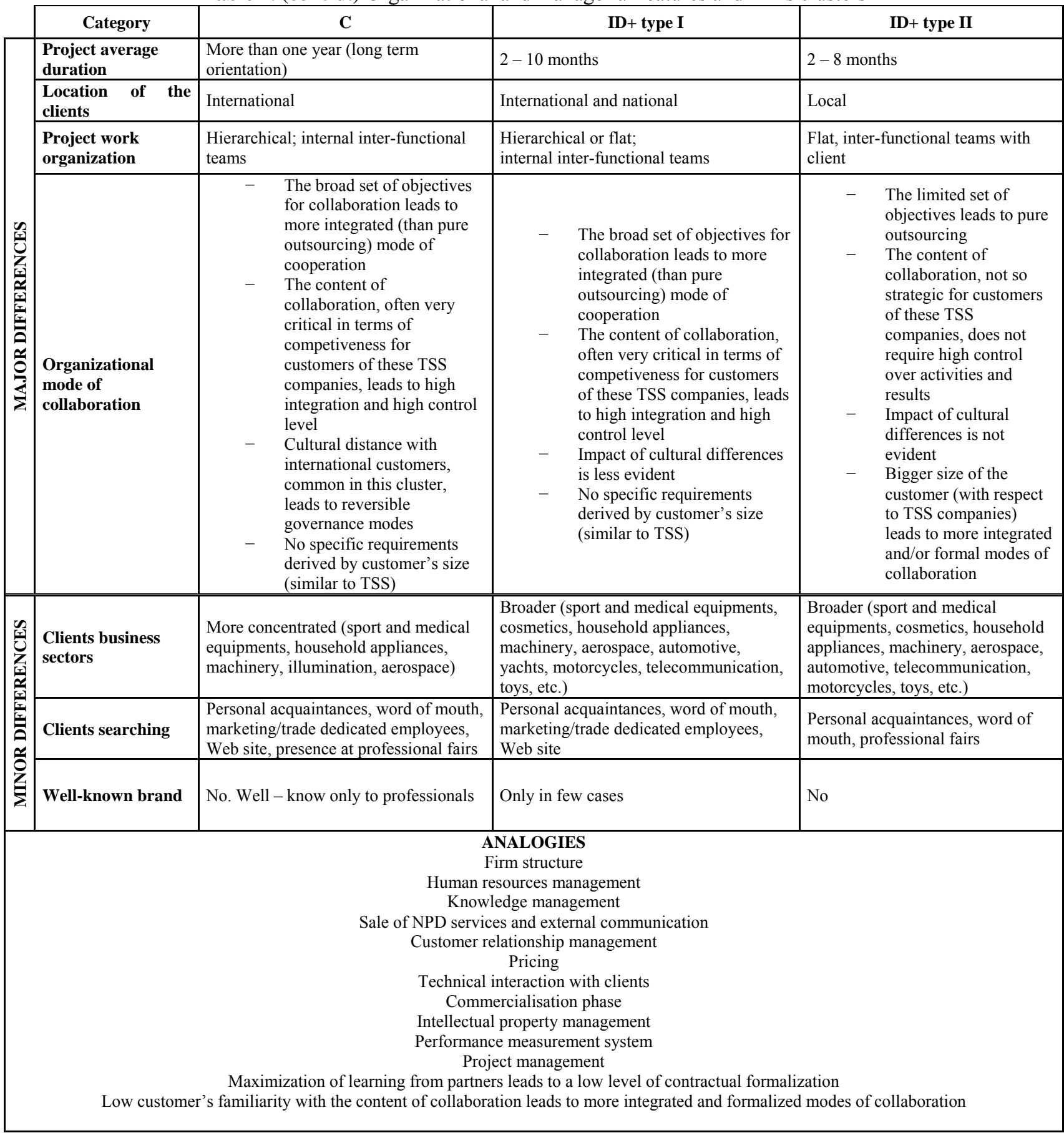

\section{Conclusions, limitations and future research}

In coherence with the main objective stated in the introduction, the paper illustrates a set of Italian firms offering services for New Product Development, from a firm-perspective. The business model adopted by these companies is described in terms of organisation, internationalisation and commercialisation strategy, organisation and management of the NPD projects. This result represents a step further in the literature that tries to study the emerging "market of technology" from a firm-perspective.

The analysis of the firms' business models can be useful for firms operating in the NPD services market, since it increases the knowledge about this sector and identifies the main features and capabilities that should be developed to pursue such business models. 
Moreover, it can be relevant for firms searching for services to support their internal NPD processes. As a matter of fact, they usually completely ignore which kind of services they may find available in the NPD service market and how these NPD companies actually carry out their business. In other words, a better knowledge of the NPD service companies may facilitate an efficient and effective relationship with their potential clients. The identification of clusters is particularly relevant from this point of view: each cluster clearly identifies a specific set of services offered and a definite approach to the management of the business, so that each company searching for external support can select the "set" of potential suppliers most adequate to its specific needs and characteristics.

The study obviously has some limitations. First, because of the adopted research methodology, results cannot be statistically generalised. Moreover, even if the internal validity of the empirical results is ensured by the cross-case analysis, the study does not explicitly take into account the effects that other contextual factors (e.g. industry features, appropriability regimes, TSS company's strategy) are likely to have on the NPD services provision. Therefore, in terms of future research, the aim is threefold in order to deepen the study of:

- NPD services dedicated to specific sectors of activity, in order to better understand the impact of industry-specific characteristics on the development of services for NPD;

- NPD companies in different countries than Italy;

- Firms covering one phase of the new product development (design companies, engineering companies, prototyping companies etc.).

These studies would offer the opportunity to conduct cross-industry and cross-country comparisons and to deepen the analysis of the main organisational and managerial features highlighted in this paper.

\section{References}

Abetti P.A., 1989. Technology: a key strategic resource. Management Review, Vol. 78, No. 2, pp. 37-41.

Arora A., Fosfuri A. and Gambardella A., 2001. Markets for Technology: the Economics of Innovation and Corporate Strategy. MIT Press, Cambridge.

Chiaroni D., Chiesa V., De Massis A. and Frattini F. 2008. The knowledge-bridging role of Technical and Scientific Services in knowledge-intensive industries. International Journal of Technology Management, Vol. 41, No. 3-4, pp. 249-272.

Chiesa V., 2001. R\&D Strategy and Organization, managing technical change in dynamic contexts, Imperial College Press.

Chiesa V. and Manzini R., 2000. Is there a market for technical knowledge? Workshop on innovation in the knowledge economy European Perspectives, Nijmegen Business School, 5-6 June.

Chiesa V. and Manzini R., 2001. Innovation and the growing market for technical and scientific services. Workshop on Management and Innovation Services, Maastricht, 5-6 April.

Chiesa V., Frattini F. and Manzini R., 2008. Managing and organising technical and scientific service firms: a taxonomy and an empirical study. International Journal of Services Technology and Management, Vol. 10, No. 2/3/4, pp. 211-234.

Chiesa V., Manzini R. and Pizzurno E., 2004. The externalisation of R\&D activities and the growing market of product development services. R\&D Management, Vol. 34, No. 1, pp. 65-75.

Cooper R. G., 1994. Perspective - Third Generation New Product Processes. Journal of Product Innovation Management, Vol. 11, No. 1, pp. 3-14.

Cooper R.G., 2008. Perspective: The stage-gates idea-to-launch process-Update, what's new, and nexGen Systems. Journal of Product Innovation Management, Vol. 25, No. 3, pp. 213-232.

Debackere K., 1999. Technologies to develop technology, Nijgmen Business School.

den Hertog P. and Bilderbeek R., 2000. The new knowledge infrastructure: the role of technology-based knowledge-intensive business services in national innovation systems, in Boden, M., Miles, I., Services and the Knowledge-Based Economy. Continuum, London.

Eisenhardt K.M., 1989. Building theories from case study research. Academy of management review, Vol. 14, No. 4, pp. 532-550.

Emes M., Hughes I. and Smith A., 2005. Internal invention, external development, R\&D Management Conference 2005, Pisa July 5-8.

Folta T.B., 1998. Governance and uncertainty: the trade-off between administrative control and commitment, Strategic Management Journal, Vol.19, pp.1007-1028.

Ginsberg A. and Abrahamson E., 1991. Champions of change and strategic shifts: the role of internal and external change advocates. Journal of Management Studies, Vol. 28, No. 2, pp. 173-190.

Haden P., Sibony O. and Sneader K. 2004, New strategies for consumer goods. The McKinsey Quarterly, Web exclusive, December 2004.

Hargadon A. and Sutton R., 1997. Technology brokering and innovation in a product development firm. Administrative Science Quarterly Dec. 1997 Vol. 42, No. 4, pp. 716-750.

Hendry J., 1995. Culture, Community and Networks: The Hidden Cost of Outsourcing. European Management Journal, Vol.13, No.2, pp.193-200. 
Hermens A., 2001. Knowledge exchange in strategic alliances: learning in tension, Creativity and Innovation Management, Vol.10, No.3, pp.189-200.

Horgos D. and Koch A., 2008. The internal differentiation of the KIBS sector: empirical evidence from cluster analysis. International Journal of Services Technology and Management, Vol. 10, No. 2/3/4, pp. 190-210.

Howells J., 1999. Research and technology outsourcing. Technology Analysis and Strategic Management, Vol. 11, No. 1, pp. 1729.

Jones O. and Stevens G., 1999. Evaluating failure in the innovation process: the micropolitics of new product development. $R \& D$ Management, Vol. 29, No. 2, pp. 167-176.

Jurgens U., 2000. New product development and production networks. Springer, Berlin.

Kelly T., 2001. The art of innovation - lessons in creativity from IDEO, American's leading design firm. Doubleday, New York.

Knoben J. and Oerlemans L.A.G., 2006. Proximity and inter-organizational collaboration: A literature review. International Journal of Management Reviews. Vol. 8, No. 2, pp. 71-89.

Kotler P. 1997. Marketing management analysis: planning, implementation and control. Prentice Hall, New Jersey USA.

Larsen J.N., 2000. Supplier-User Interaction in Knowledge-Intensive Businee Services: Types of Expertise and Modes of Organization, in Boden, M., Miles, I., Services and the Knowledge-Based Economy. Continuum, London.

Lazzarotti V. and Manzini R., 2009. Different modes of open innovation: a theoretical framework and an empirical study. International Journal of Innovation Management, Vol. 13, No. 4, pp. 615-636.

Lawson B., Petersen K.J., Cousins P.D. and Handfield R.B. 2009. Knowledge Sharing in Interorganizational Product Development Teams: The Effect of Formal and Informal Socialization Mechanisms. The Journal of Product Innovation Management, Vol.26, pp.156-172.

MacPherson A.., 1997a. The contribution of external services inputs to the product development efforts of small manufacturing firms. R\&D Management, Vol. 27, No. 2, pp. 127-144.

MacPherson A.., 1997b. The role of external technical support in the innovation performance of scientific instruments firms: empirical evidence from New York State. Technovation, Vol. 17, No. 3, pp. 141-150.

Miles I., 2000. Services innovation: coming of age in the knowledge-based economy. International Journal of Innovation Management, Vol. 4, No. 4, pp. 371-389.

Miles M.B. and Huberman A.M., 1984. Qualitative Data Analysis. Newbury Park: Sage.

Muller E. and Zenker A., 2001. Business services as actors of knowledge transformation: the role of KIBS in regional and national innovation systems. Research Policy, Vol. 30, No. 9, pp. 1501-1516.

Ojasalo J. 2008. Management of innovation networks: a case study of different approaches. European Journal of Innovation Management, Vol.11, No.1.

Quinn J.B., 1999. Strategic outsourcing: leveraging knowledge capabilities. Sloan Management Review, Vol. 40, No. 4, pp. 9-21.

Quinn J.B., 2000. Outsourcing innovation: the new engine of growth. Sloan Management Review, Vol. 41, No. 4, pp. 13-28.

Rundquist J. and Chibba A. 2004. The use of processes and methods in NPD: a survey of Swedish industry. International Journal of Innovation and Technology Management, Vol. 1, No. 1, pp. 37-54.

Strambach S., 2008. Knowledge-Intensive Business Services KIBS as drivers of multilevel knowledge dynamics. International Journal of Services Technology and Management, Vol. 10, No. 2/3/4, pp. 152 -174.

Tidd J., 1995. Development of novel products through intraorganizational and interorganizational networks. Journal of Product Innovation Management, Vol. 12, No. 4, pp. 307-322.

Trott P., 2008. Innovation management and new product development. Prentice Hall, New Jersey.

Urban G.L. and Hauser J.R., 1993. Design and Marketing of New Products, 2nd edition. Prentice Hall, Upper Saddle River USA.

van de Vrande V., Lemmens C. and Vanhaverbeke, W., 2006. Choosing governance modes for external technology sourcing. $R \& D$ Management, Vol. 36, No.3., pp.347-363.

Varela J. and Benito L. 2005. New product development process in Spanish firms - typology, antecedents and technical marketing activities. Technovation, Vol. 25, No. 4, 395-405.

Verganti R., 1997. R\&D Management. Blackwell Publishers, Oxford.

Veugelers R. and Cassiman B., 1999. Make and Buy in innovation strategies: evidence from Belgian manufacturing firms, Research Policy, Vol. 28, No. 1, pp. 63-80.

Williamson O.E., 1985. The Economic Institutions of Capitalism: Films, Markets, Relational Contracting. New York, NY: Free Press.

Windrum P. and Tomlison M., 1999. Knowledge-intensive Services and international competitiveness: a four-country comparison. Technology Analysis and Strategic Management, Vol. 11, No. 3, pp. 391-405.

Yin R. K., 2003. Case study research, design and methods. $3^{\text {rd }}$ ed. Sage Publications, Thousand Oaks.

Zenker A. and Doloreux D., 2008. KIBS, perceptions and innovation patterns. International Journal of Services Technology and Management, Vol. 10, No. 2/3/4, pp. 337-342. 


\section{Biographical notes}

Valentina Lazzarotti is Assistant Professor at the Faculty of Engineering of University Carlo Cattaneo - LIUC. She teaches Business Economics and Organization and Management Control Systems at LIUC. She obtained her Master Degree in Business Administration from Bocconi University. Her research interests concern R\&D performance measurement and accounting for innovative activities. She has published papers in international journals such as International Journal of Innovation Management and Project Management Journal.

Emanuele Pizzurno, PhD, is currently Assistant Professor in the management area at the Faculty of Engineering of the University Carlo Cattaneo - LIUC where he developed most of his academic activities. He is also research fellow and professor at the Scuola Mattei - Eni Corporate University and at the Department of Management Engineering at Politecnico di Milano. The major research and teaching topics concern innovation and technology management and the organization of $\mathrm{R} \& \mathrm{D}$; he has also long studied environmental strategies and management. On these issues, he is the author of several scientific publications.

Received June 2010

Accepted November 2010

Final acceptance in revised form November 2010 